\title{
Essais sur la concentration des ferments lactiques utilisés pour la maturation des crèmes
}

\author{
par \\ R. LACROSSE \\ Chef de Section à la Station laitière de l'Etat à Gembloux
}

\section{1) Introduction}

Depuis un certain nombre d'années, les laboratoires de recherches tant officiels que privés ont étudié les modalités de concentration des ferments et les possibilités offertes par leur utilisation en industrie laitière.

La Station centrale de Recherches laitières et de Technologie des produits animaux à Jouy-en-Josas s'est attachée, par des études successives dues à différents chercheurs $[1,2,3,4]$, à mettre au point les techniques de préparation de suspensions concentrées lactiques thermophiles destinées à la fromagerie.

Les chercheurs du NIZO à Ede ont étudié les facteurs de production de grandes quantités de bactéries dans les levains lactiques [5].

Les résultats de ces recherches ont déjà reçu certaines applications pratiques et des firmes commerciales privées ont mis sur le marché des ferments concentrés congelés qui sont utilisés actuellement dans le domaine de la fromagerie et la fabrication des yoghourts.

L'utilisation des ferments concentrés ne connaît pas encore beaucoup d'applications dans le domaine de la beurrerie et les essais que nous avons réalisés ont eu pour but d'apprécier les possibilités d'utilisation des suspensions concentrées dans la technologie beurrière.

\section{2) Milieu utilisé pour la culture des ferments lactiques}

Le milieu de culture utilisé pour la multiplication des ferments lactiques avait la composition suivante :

0,5 p. 100 Extrait de viande

1 p. 100 Tryptone

0,5 p. 100 Peptone

0,5 p. 100 Lactose 
Ensemencement à 1 p. 100 et culture 24 h à $30^{\circ} \mathrm{C}$.

Nous avons utilisé une souche de levain normale où les deux types de bactéries utilisées normalement pour la maturation des crèmes étaient représentées, le Streptococcus diacetylactis et le Leuconostoc cremoris.

\section{3) Méthode de préparation}

La concentration des ferments était réalisée par une super-centrifugeuse Sharpless de laboratoire, vitesse de rotation du bol 25000 $\mathrm{t} / \mathrm{mn}$ soit $\pm 17000 \mathrm{~g}$.

Nous avons déterminé qu'à cette vitesse toutes les cellules restaient sur la paroi intérieure du bol, la partie rejetée lors de la centrifugation étant pratiquement indemne de cellules vivantes de ferments lactiques.

\section{4) Milieu de culture utilisé pour le dénombrement des bactéries lactiques}

Le milieu de culture utilisé a été étudié par Nickels et Leesment et remis spécialement au point par G. Waes [6]. Ce milieu donne entière satisfaction si l'on a soin d'éviter toute contamination par les moisissures, celles-ci envahissant très rapidement la surface des boîtes de Pétri.

COMPOSITION DU MILIEU DE CULTURE

\section{Milieu de base}

$\begin{array}{llrr}\text { Tryptone } & : & 20 & \mathrm{~g} \\ \text { Yeast extract } & : & 5 & \mathrm{~g} \\ \text { Gelatine } & : & 2,5 & \mathrm{~g} \\ \text { Glucose } & : & 5 & \mathrm{~g} \\ \text { Lactose } & : & 5 & \mathrm{~g} \\ \mathrm{NaCl} & : & 4 & \mathrm{~g} \\ \text { Citrate de } \mathrm{Na} & : & 2 & \mathrm{~g} \\ \text { Lactate de calcium } & : & 8 & \mathrm{~g} \\ \text { Agar } & : & 15 & \mathrm{~g}\end{array}$

Eau distillée $1000 \mathrm{ml}$ - pH final du milieu 6,6 - 6,7.

Milieu à base de sérum de lait

A partir du lait emprésuré et filtré, on recueille le sérum qui est stérilisé $10 \mathrm{mn}$ à $115^{\circ} \mathrm{C}$.

\section{Suspension de citrate de calcium}

$10 \mathrm{~g}$ de citrate de calcium sont mélangés au mixer avec une solution à 1,5 p. 100 de Carboxyméthylcellulose.

Le milieu de base sera complété par 10 p. 100 de sérum de lait et 5 p. 100 de la solution de citrate de calcium.

Incubation des boîtes de Pétri : $4 \mathrm{j}$ à $25^{\circ} \mathrm{C}$. 


\section{5) Dénombrement des bactéries lactiques avant et après concentration}

\begin{tabular}{|c|c|}
\hline $\begin{array}{c}\text { Ferments avant concentration } \\
\text { (nombre de cellules par ml de } \\
\text { milieu de culture) }\end{array}$ & $\begin{array}{l}\text { Ferments après concentration } \\
\text { (nombre de cellules par ml } \\
\text { après dilution du concentrat) }\end{array}$ \\
\hline $\begin{array}{r}1,6 \times 10^{9} \\
1,7 \times 10^{7} \\
5 \times 10^{7} \\
2,4 \times 10^{6} \\
2 \times 10^{6} \\
2,9 \times 10^{6} \\
1,9 \times 10^{8} \\
3,7 \times 10^{6} \\
6,6 \times 10^{6} \\
5 \times 10^{6} \\
5 \times 10^{8} \\
126 \times 10^{6} \\
14 \times 10^{8} \\
18 \times 10^{6} \\
35 \times 10^{5} \\
10 \times 10^{6} \\
1,2 \times 10^{6}\end{array}$ & $\begin{aligned} 6 & \times 10^{9} \\
28 & \times 10^{7} \\
22 & \times 10^{8} \\
5,7 & \times 10^{8} \\
12 & \times 10^{7} \\
21 & \times 10^{7} \\
14 & \times 10^{7} \\
1 & \times 10^{7} \\
8,8 & \times 10^{8} \\
22 & \times 10^{7} \\
37 & \times 10^{7} \\
83 & \times 10^{7} \\
38 & \times 10^{7} \\
84 & \times 10^{7} \\
152 & \times 10^{8} \\
91 & \times 10^{7} \\
55 & \times 10^{7}\end{aligned}$ \\
\hline
\end{tabular}

Les dénombrements sur les ferments concentrés ont été effectués sur le concentrat recueilli dans le bol de la centrifugeuse et remis en solution dans $20 \mathrm{ml}$ de lait stérilisé ou dans $20 \mathrm{ml}$ d'une solution contenant 50 p. 100 de glycérine stérile et 50 p. 100 d'eau stérile.

Pour les 17 essais effectués, on obtient le nombre moyen de $27 \times 10^{\circ}$ cellules vivantes par $\mathrm{ml}$ dans le milieu de culture et dans le concentrat remis en solution $861 \times 10^{6}$ cellules vivantes par ml.

Avant la remise en solution du concentrat, on peut estimer que la concentration est d'environ 200 fois le nombre de cellules initiales.

\section{6) Conservation des ferments concentrés en congélation à $-20^{\circ} \mathrm{C}$}

Les essais de conservation ont porté sur cinq préparations de ferments concentrés congelés à $-20^{\circ} \mathrm{C}$ et remis en solution dans du lait stérilisé (50 p. 100 de concentrat et 50 p. 100 de lait stérilisé).

La durée de conservation des ferments concentrés congelés à $-20^{\circ} \mathrm{C}$ n'est donc pas supérieure à 3 mois, passé ce délai de conservation, la proportion de bactéries survivantes devient très faible.

Pour obtenir une durée de conservation de 3 mois, la température devrait être abaissée à $-30^{\circ} \mathrm{C}$. Dans ces conditions de conservation, les ferments congelés gardent leur activité à 90 p. 100, la durée de conservation peut aller jusqu'à 6 mois et plus en azote liquide $\left(-196^{\circ} \mathrm{C}\right)$. 


\begin{tabular}{|c|c|c|c|}
\hline \multirow{2}{*}{$\begin{array}{c}\text { Teneur initiale en } \\
\text { bactéries lactiques } / \mathrm{ml}\end{array}$} & \multicolumn{3}{|c|}{ Conservation à $-20^{\circ} \mathrm{C}$} \\
\hline & 2 mois & 3 mois & 4 mois \\
\hline $\begin{array}{l}28 \times 10^{7} \\
22 \times 10^{s} \\
83 \times 10^{7} \\
91 \times 10^{7} \\
39 \times 10^{7}\end{array}$ & $\begin{array}{l}24 \times 10^{7} \\
17 \times 10^{8} \\
70 \times 10^{7} \\
72 \times 10^{7} \\
14 \times 10^{7}\end{array}$ & $\begin{array}{l}15 \times 10^{7} \\
80 \times 10^{7} \\
45 \times 10^{7} \\
50 \times 10^{7} \\
10 \times 10^{7}\end{array}$ & $\begin{aligned} 4 & \times 10^{7} \\
15 & \times 10^{7} \\
7 & \times 10^{z} \\
7 & \times 10^{7} \\
2 & \times 10^{7}\end{aligned}$ \\
\hline Moyenne $92 \times 10^{7}$ & $70 \times 10^{7}$ & $40 \times 10^{7}$ & $7 \times 10^{7}$ \\
\hline
\end{tabular}

7) Essais d'utilisation des ferments concentrés pour la culture des levains. Comparaison avec le pouvoir d'acidification du ferment cultivé normalement

Les ferments concentrés ont été utilisés le jour-même de leur préparation. La teneur en bactéries du ferment concentré : $22 \times 10^{7}$ bactéries par $\mathrm{ml}$.

\begin{tabular}{|c|c|c|c|}
\hline & & \multicolumn{2}{|c|}{ Acidité en degrés Dornic } \\
\hline & & $18 \mathrm{~h}$ à $22^{\circ} \mathrm{C}$ & $18 \mathrm{~h}$ à $14^{\circ} \mathrm{C}$ \\
\hline $\begin{array}{l}\text { Lait }+ \text { ferment normal } \\
\text { Lait }+ \text { ferment concentré }\end{array}$ & $\begin{array}{l}0,5 \text { p. } 100 \\
0,5 \text { p. } 100 \\
0,2 \text { p. } 100 \\
0,1 \\
0.05 \text { p. } 100 \\
0,00\end{array}$ & $\begin{array}{l}80 \\
65 \\
65 \\
60 \\
57\end{array}$ & $\begin{array}{l}23 \\
40 \\
24 \\
22 \\
20\end{array}$ \\
\hline
\end{tabular}

Les ferments concentrés pourraient être utilisés pour la préparation des levains, une proportion d'ensemencement de 10 p. 100 par rapport au ferment normal donnant une acidification satisfaisante.

\section{8) Essais d'utilisation pour la maturation des crèmes}

Les expériences que nous avons conduites pour la maturation des crèmes se sont montrées dans l'ensemble assez décevantes. 
Résultats de trois essais effectués à la laiterie expérimentale

Premier essai : Maturation de crèmes à $14^{\circ} \mathrm{C}$ pendant $16 \mathrm{~h}$.

\begin{tabular}{ll|l}
\hline Modalités d'ensemencement & $\begin{array}{c}\text { Acidité en fin de maturation } \\
\text { en degrés Dornic }\end{array}$ \\
\hline 3 & p. 100 de ferment ordinaire & 37,5 \\
0,5 p. 100 de ferment concentré & 44 \\
0,3 p. 100 de ferment concentré & 37 \\
0,2 p. 100 de ferment concentré & 30 \\
0,1 p. 100 de ferment concentré & 27 \\
0,05 p. 100 de ferment concentré & 23,5 \\
\hline
\end{tabular}

Deuxième essai : Maturation à $13^{\circ} \mathrm{C}-14^{\circ} \mathrm{C}$ pendant $16 \mathrm{~h}$.

Modalités d'ensemencement

5 p. 100 de ferment ordinaire

3 p. 100 de ferment ordinaire

1 p. 100 de ferment ordinaire

0,5 p. 100 de ferment concentré

0,3 p. 100 de ferment concentré

0,2 p. 100 de ferment concentré

0,1 p. 100 de ferment concentré

0,05 p. 100 de ferment concentré
Acidité en fin de maturation en degrés Dornic

Troisième essai : Maturation à $15^{\circ} \mathrm{C}$ ( $24 \mathrm{~h}$ et $42 \mathrm{~h}$ - acidité en degrés Dornic).

\begin{tabular}{|c|c|c|}
\hline & $24 \mathrm{~h}$ & $42 \mathrm{~h}$ \\
\hline $\begin{array}{l}5 \text { p. } 100 \text { de ferment ordinaire } \\
3 \text { p. } 100 \text { de ferment ordinaire } \\
2 \text { p. } 100 \text { de ferment ordinaire } \\
1 \text { p. } 100 \text { de ferment concentré } \\
0,5 \text { p. } 100 \text { de ferment concentré } \\
0,3 \text { p. } 100 \text { de ferment concentré } \\
0,2 \text { p. } 100 \text { de ferment concentré } \\
0,1 \text { p. } 100 \text { de ferment concentré }\end{array}$ & $\begin{array}{l}32 \\
28 \\
23 \\
24 \\
30 \\
23 \\
22 \\
18\end{array}$ & $\begin{array}{l}48 \\
37 \\
37 \\
55 \\
43 \\
47 \\
37 \\
37\end{array}$ \\
\hline
\end{tabular}

Divers autres essais de maturation de crèmes effectuées à $11-12^{\circ} \mathrm{C}$ ne nous montrent aucune acidification dans les crèmes ensemencées au moyen des ferments concentrés.

\section{9) Commentaires et conclusions}

Les résultats enregistrés indiquent que la quantité de ferments concentrés nécessaires pour obtenir une acidification suffisante dans 
les crèmes mises en maturation est très importante et qu'il n'est pratiquement pas possible d'envisager leur utilisation directe pour l'ensemencement des crèmes.

Pour l'ensemencement de $1000 \mathrm{~kg}$ de crème on utilise ordinairement $50 \mathrm{~kg}$ de levain cultivé normalement, il serait nécessaire d'utiliser $5 \mathrm{~kg}$ de ferment concentré pour obtenir une acidification sensiblement égale, cette quantité très importante enlève tout intérêt à l'utilisation pratique des ferments concentrés.

L'emploi des ferments concentrés peut être envisagé pour la culture des levains lactiques destinés à l'ensemencement des crèmes, les études devraient être orientées à l'avenir vers la sélection de souches adaptées à la croissance à plus basse température.

\section{Rés u m é}

L'auteur expose les résultats des essais ayant pour objet l'étude de l'utilisation pratique des ferments concentrés en beurrerie.

Les techniques de culture des ferments et de numération des bactéries lactiques sont détaillées ainsi que les essais de conservation des ferments concentrés à $-20^{\circ} \mathrm{C}$.

Les essais d'utilisation des ferments concentrés se sont montrés satisfaisants en ce qui concerne la préparation des levains destinés à la maturation des crèmes où environ 10 p. 100 de la quantité de ferment cultivé normalement est indispensable (environ 0,03 à 0,05 p. 100).

Pour l'ensemencement direct des crèmes on ne peut préconiser leur utilisation car les quantités de ferments concentrés deviennent trop importantes étant donné que les maturations des crèmes s'effectuent à des températures assez basses (inférieures à $14^{\circ} \mathrm{C}$ ) leur pouvoir d'acidification est pratiquement très faible.

\section{S u $\mathrm{m} \mathbf{m}$ a r y}

The author exposes methods of preparation, enumeration of concentrated starters used in the practice of buttermaking.

For the utilisation, he finds good performances with the inoculation of mother and daughter starters, 5 to 10 p. 100 of the amount of normal starters are necessary to assure a suffisant acidification (at $22^{\circ} \mathrm{C}$ ).

It is not possible to use the concentrated starters for direct inoculation of creams, the amount are too important because the temperature of fermentation $\left(11^{\circ} \mathrm{C}-14^{\circ} \mathrm{C}\right)$ generally adopted in the actuel butter technology. 


\section{Bibliographie}

[1] Vallès (E.) et Mocouot (G.) (1968). - Préparation de suspensions concentrées et congelées de bactéries lactiques thermophiles destinées à la fromagerie. Le Lait, 48, 631-643.

[2] Bergère (J. L.) (1968). - Production massive de cellules de streptocoques lactiques. Le Lait, 48, 1-11.

[3] Bergère (J. L.) et Hermier (J.) (1968). - Production massive de cellules de streptocoques lactiques. Le Lait, 48, 13-30.

[4] Accolas (J. P.) et Auclair (J.) (1967). - Conservation à l'état congelé de suspensions de bactéries lactiques concentrées sous faible volume, Le Lait, $47,253-260$.

[5] Stadhouders (J.), Jansen (L. A.) and Hup (G.) (1969). - Preservation of Starters and mass production of Starter bacteria. Nederlands Melk en Zuiveltijdschrif, 23, 182-199.

[6] Waes (G.) (1968). - The enumeration of aromabacteria in B.D. Starters. Nederlands melk en Zuiveltijdschrift, 1-2, 29 à 39. 